Sādhanā Vol. 40, Part 7, October 2015, pp. 2263-2270. (C) Indian Academy of Sciences

\title{
Visualization of soil arching in flexible piled embankments
}

\section{TUĞBA ESKIŞAR}

\author{
Ege University, Civil Engineering Department, Geotechnics Division, 35100 Izmir, \\ Turkey \\ e-mail: tugba.eskisar@ege.edu.tr
}

MS received 13 May 2014; revised 15 April 2015; accepted 1 June 2015

\begin{abstract}
Piled embankments rely on soil arching, but, when geogrid reinforcements are used, membrane action within the reinforcement contributes to load distribution. The arching of soil in unreinforced and reinforced piled embankments is evaluated in this study. A small-scale test apparatus is used to model the settlement up to $5 \mathrm{~mm}$ in an embankment with four pile elements. Visual inspection of the soil settlement and soil-reinforcement interaction is important to explain the mechanism of arching. In this study, X-ray Computed Tomography (CT) method was used as a non-destructive technique. The arching of soil between the piles was observed in the case of rigid piles and in the case of flexible piles with grid type of reinforcement. The load carrying capacity increased up to $33 \%$ in the case of geogrid reinforcement, and the differential settlement decreased around 35\%, proving the efficiency of piled embankments with geogrid reinforcements. It is also shown that, using X-ray CT method and visualization techniques provides a better understanding of soil behavior in a reinforced embankment with the flexible pile foundation system.
\end{abstract}

Keywords. Soil; pile; geogrid; arching; non-destructive testing.

\section{Introduction}

The presence of good quality soils for construction is becoming rare worldwide and for this reason it is sometimes necessary to construct structures on soils which are considered as unsuitable. When infrastructures like embankments over soft soils are concerned, geotechnical engineers encounter with many problems such as potential bearing failure, intolerable settlements, and instability. However, constructing embankments with piles and geogrid reinforcements provide a cost-effective solution for the purpose of reducing differential settlements. During the construction process, the geogrid is laid on the pile elements and placed in the soft ground. As a result, the load transmitted to the pile elements is shared effectively within the pile without transferring to the subsoil between the elements. In the pile-geogrid reinforcement system, the geogrid behaves like a tensioned membrane and the arching effect taking place on the top of the piles prevents the differential settlements.

Arching of soils has been a subject of interest among the researchers and different approaches are available for calculating the stress acting on piles caused by arching of soils (Terzaghi 1943; 
Handy 1985; Guido et al 1987; Hewlett \& Randolph 1988; Mc Kelvey 1994; Russel \& Pierpoint 1997; Han \& Gabr 2002; Kempfert et al 2004; Jenck 2007; Abusharar et al 2009; BS 8006 2010; EBGEO 2010; Van Eekelen et al 2012a, b, 2013). Visual inspection of the soil under a certain settlement and interaction between soil and reinforcements is important to explain the mechanism of load transfer, and the preliminary results of this study would provide a better understanding of the arching mechanism.

$\mathrm{X}$-ray Computed Tomography (CT) is one of the non-destructive testing methods, which can be used to evaluate the properties of geomaterials, and it provides cross sectional images based on the absorption of the X-ray beam through the materials (Otani 2003). In this study, a series of laboratory model tests was performed on piled embankments. The load transfer of unreinforced and reinforced embankments with rigid and flexible pile foundations was scanned using industrial X-ray CT. Based on the results, the effect of reinforcement is evaluated and behavior of the pile-soil system is discussed. Quantitative evaluation of the load transfer mechanism is explained with the help of CT images. Using X-ray CT method and visualization techniques provided a better understanding of soil arching in piled embankments.

\section{X-ray CT method}

\subsection{Fundamentals}

$\mathrm{X}$-ray CT is a non-destructive testing technique that allows imaging and quantification of internal features of an object in three dimensions. The method reveals differences in density and atomic composition. The principle of the measurement consists of two steps: first, recording Xray radiographies of a specimen at several different angular positions with a full angle of at least $180^{\circ}$ and then, reconstructing virtual slices from these different projections, using appropriate algorithms which are either algebraic or based on a back projection principle. Stacking several sequential slices allows reconstructing a three-dimensional image of the object (Otani 2003).

CT images are constructed by the spatial distribution of so-called "CT-value" and this is defined as (Kak \& Slaney 1988):

$$
C T \text {-value }=\frac{\mu_{t}-\mu_{w}}{\mu_{w}} K
$$

where $\mu_{t}$ is the coefficient of absorption at scanning point, $\mu_{w}$ is the coefficient of absorption for water, and $K$ is a constant (Hounsfield value). Here, it is noted that this constant is fixed to a value of 1,000. Thus, the CT-value of air should be $-1,000$ because the coefficient of absorption for air is zero. Likewise, CT-value for water is 0 from the definition of Eq. (1).

CT images are presented with shaded gray or black color for low CT-value and light gray or white color for high CT-value in all the subsequent black and white colors. The total number of levels on these colors is 256. It is known that this CT-value is linearly related to the material density (Kak \& Slaney 1988). Figure 1 shows the relationship between CT-value and dry density of Toyoura sand which was used in this study. From this figure, it is confirmed that there is a linear relationship between CT-value and the density of the material and this relationship depends on the scanning conditions such as X-ray attenuation, and the size and shape of the scanning materials. Therefore, the size and shape of the scanning materials have to be fixed for all the comparative studies.

In general, a digital image is composed of "pixel" in two dimensions, but so-called "voxel" is used for X-ray CT image because the CT image is constructed not in two dimensions but in three 


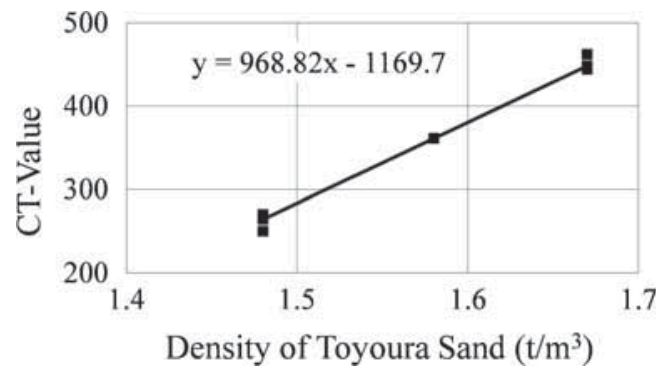

Figure 1. Relationship between CT-value and density of Toyoura sand used in this study.

dimensions. Therefore, the value of X-ray absorption can be defined as the density in each voxel. In this study, X-ray CT images presented the density of a voxel which is the size of $0.293 \mathrm{~mm} \times$ $0.293 \mathrm{~mm} \times 1 \mathrm{~mm}$.

\subsection{System of X-ray CT scanner}

There are several types of X-ray CT scanner systems differentiated by factors such as the scanning time or the number of detectors. The system used in this study belongs to the second generation, which is known to give the most accurate results, but has longer scanning time equipment than all others of the fan beam type. In this apparatus, the collimated X-ray is penetrated from all around the circumference of the specimen by rotating and translating the specimen table. The detected data are assembled and the cross sectional images are reconstructed using image data processing device by means of filtered back-projection method (Kak \& Slaney 1988). Then, the image is expressed on the monitor of engineering workstation. By accumulating the entire cross sectional images around the circumference of the specimen, the three dimensional images can be reconstructed.

While the medical CT scanners are most commonly equipped with $140 \mathrm{kV}$ X-ray tubes, the industrial scanners are equipped up to $300 \mathrm{kV}$ X-ray tubes. Voltage for X-ray tube alimentation of $200 \mathrm{kV}$ was used in this study. As the capacity of the industrial scanner is higher than the medical scanner, quantitative discussion is expected.

\section{Model tests}

\subsection{Test apparatus}

Small scale testing is the only possibility when X-ray CT scanning techniques are used due to the specifications of the device. It is essential to also consider the scaling rules for small scale tests. The tests are usually scaled between 1:20 and 1:55 for modeling purposes. In this study, the geometric scale is preferred as 1:30, to provide compatibility with X-ray CT. The soil box in the test apparatus is an acrylic mold having a height of $200 \mathrm{~mm}$, and a diameter of $126 \mathrm{~mm}$. The pile diameter is $d=15 \mathrm{~mm}$. Four model piles constituting a grid shape with a distance of 3 pile-diameter $(l=45 \mathrm{~mm}$ ) are fixed at the bottom (figure 2). The reason for having four piles in the apparatus is that four piles are a unit of a large number of piles for the real construction site as far as 3D behavior is concerned.

At the beginning of the test, the settlement plate is at the same level as the pile heads. The piles can penetrate the settlement plate, which is set at the bottom of the fill. This settlement plate 

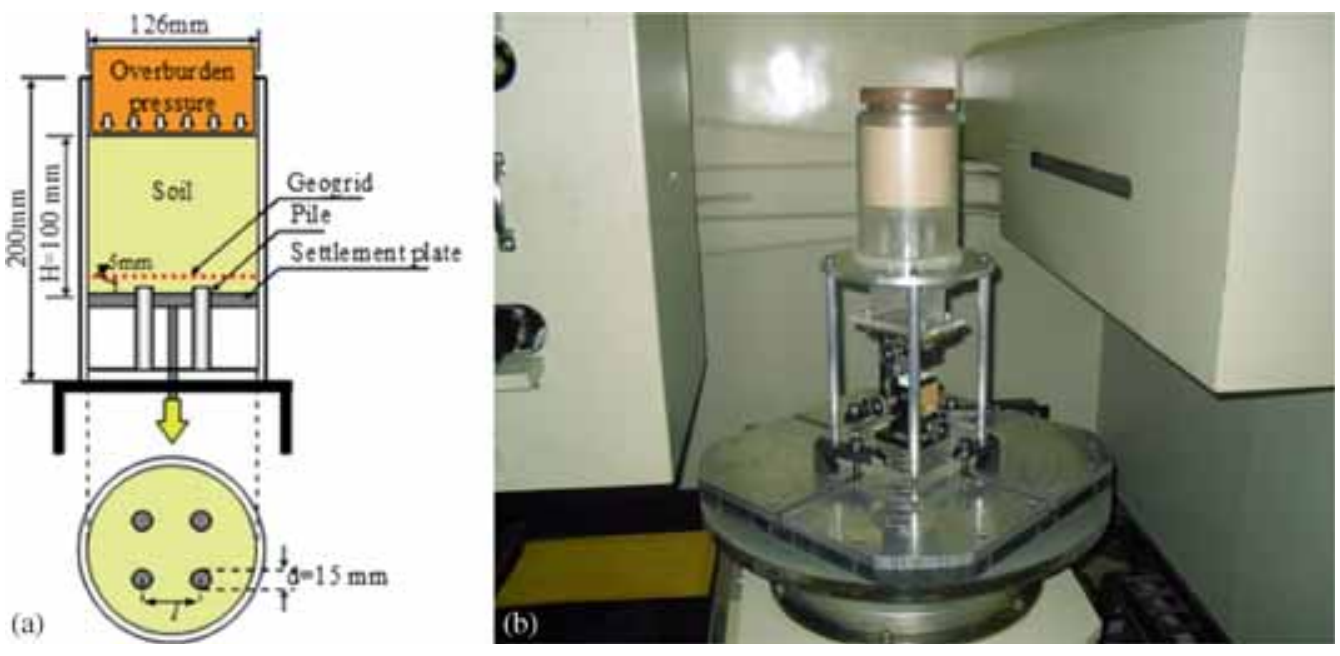

Figure 2. The settlement test apparatus.

Table 1. Material properties of Toyoura sand.

\begin{tabular}{llr}
\hline Maximum dry density, $\gamma_{\mathrm{d}, \max }$ & $\left(\mathrm{t} / \mathrm{m}^{3}\right)$ & 1.65 \\
Minimum dry density, $\gamma_{\mathrm{d}, \min }$ & $\left(\mathrm{t} / \mathrm{m}^{3}\right)$ & 1.33 \\
Effective particle size, $\mathrm{D}_{50}$ & $(\mathrm{~mm})$ & 0.19 \\
Uniformity coefficient, Uc & $(-)$ & 1.56 \\
Internal friction angle, $\phi$ & $\left({ }^{\circ}\right)$ & 39.4 \\
\hline
\end{tabular}

is controlled by a manually adjustable XYZ stage apparatus existing under the soil box and the method of moving down this settlement plate is assumed to be the consolidation settlement of the subsoil due to the embankment loading. For each experiment, initial condition and settlements of $5 \mathrm{~mm}$ were scanned with $1 \mathrm{~mm}$ intervals for a maximum height of $40 \mathrm{~mm}$ above the settlement plate.

\subsection{Materials}

In this study, Toyoura sand was used. The relative density of Toyoura sand is $80 \%$ for all test cases. The material properties of Toyoura sand are given in table 1. The height of Toyoura sand in the soil box was $100 \mathrm{~mm}$ in every case. The overburden pressure of $3.2 \mathrm{kPa}$ was applied as dead-load in order to apply a relatively large confining pressure.

As a reinforcing material, a rubber sheet with a thickness of $0.5 \mathrm{~mm}$ was cut to $10 \mathrm{~mm} \times$ $10 \mathrm{~mm}$ grids. In reinforced case, it was placed at $5 \mathrm{~mm}$ above from the settlement plate. The objective of working with gridded pattern rubber sheet was to visualize the behavior of a semicontinuous membrane in this preliminary study.

The types of piles used in test cases were rigid and flexible piles, respectively. Both types of piles were made from acrylic material to be suitable for X-ray CT scanning. The flexible pile consists of a spring and a base; a casing covers the pile. The coefficient of spring in flexible pile was chosen to be $0.853 \mathrm{~N} / \mathrm{m}$ and this value was confirmed by conducting a separate physics test. 
The height of the rigid piles is $60 \mathrm{~mm}$ while the height of the flexible piles is $74 \mathrm{~mm}$ in order to leave enough length for the shortening of the spring inside the piles.

Three cases were conducted to discuss the behavior of soils with X-ray CT. The cases were named as: Case I, rigid piles without reinforcement; Case II, flexible piles without reinforcement; and Case III, flexible piles with grid type of reinforcement.

\section{Results and discussion}

The CT images are taken from the conditions of $5 \mathrm{~mm}$ settlement of the soil and the horizontal cross sectional images focusing on the piles are shown with $4 \mathrm{~mm}$ intervals in an upward direction relative to the position of the settlement plate (figure 3). As an example, the preliminary scanning results of rigid piles without reinforcement and flexible piles with grid type of reinforcement are compared. In Case I (figure 3a), high density regions are formed (light gray - gray) just above each pile element right after the settlement, and low density area formed around each pile (dark gray - black) enclosing it like a ring shape. The density change in Case III is much lighter than Case I, as the flexible piles share the overburden load with the geogrid reinforcement. This low density area that is formed at the location of geogrid, ensures that settlement of

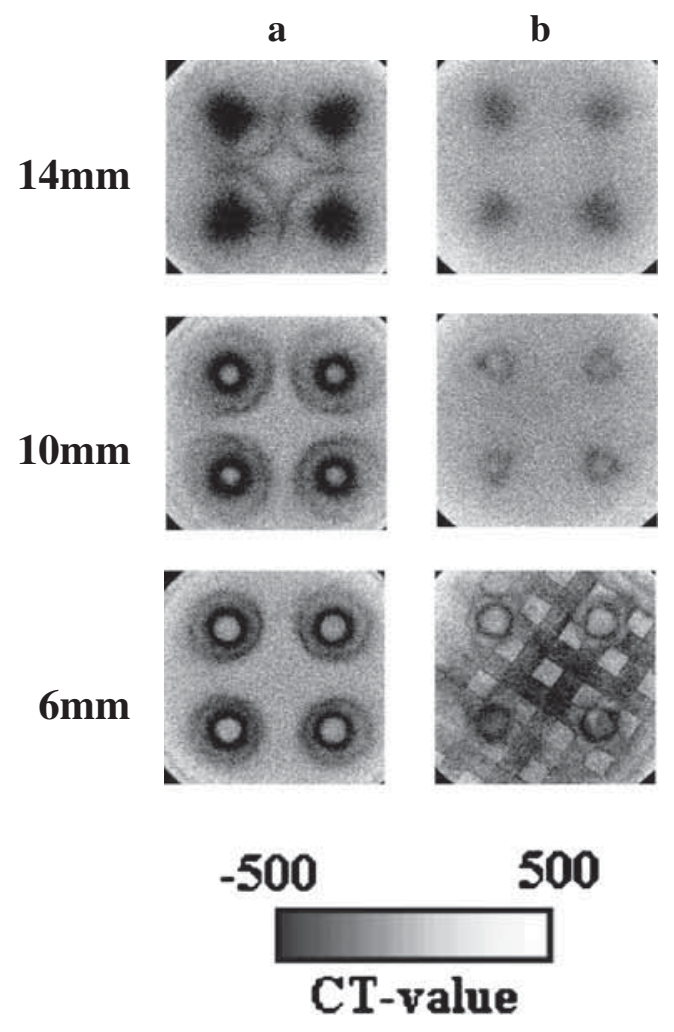

Figure 3. Horizontal cross sectional images at $5 \mathrm{~mm}$ settlement in cases of (a) rigid piles - Case I, (b) flexible piles with geogrid reinforcement - Case III. The cases are shown in $4 \mathrm{~mm}$ intervals from $6 \mathrm{~mm}$ to $14 \mathrm{~mm}$ above the settlement plate. 
soil and pile head can vary widely depending on the direction of geogrid surface. This is believed to be caused by the influence of geogrid aperture.

Figure 4 shows the results of CT scanning, which is the vertical cross sectional images in all cases at $5 \mathrm{~mm}$ settlement. After image processing, the interval of $280<$ CT-value $<540$ is used to construct the vertical images. The black dotted lines in the figures refer to the boundary of density change which is a proof of visualization of soil arching between the piles. The width of the vertical cross sections is about $90 \mathrm{~mm}$. The common behavior observed in the cases is a high density area above the pile heads, which is in the geometric shape of a circular cone.

In Case I, it is seen that, there is a significant change of density from higher to lower, forming two inclined shear planes perpendicular to the vertical cross section, intersecting with each other forming an isosceles triangular shape. The base angle of this shape is referred as the angle of density change. The angle of density change $\theta$ is shown with black dotted lines. It is seen that the density around the circumference of each pile head is decreased due to dilatancy, as a result
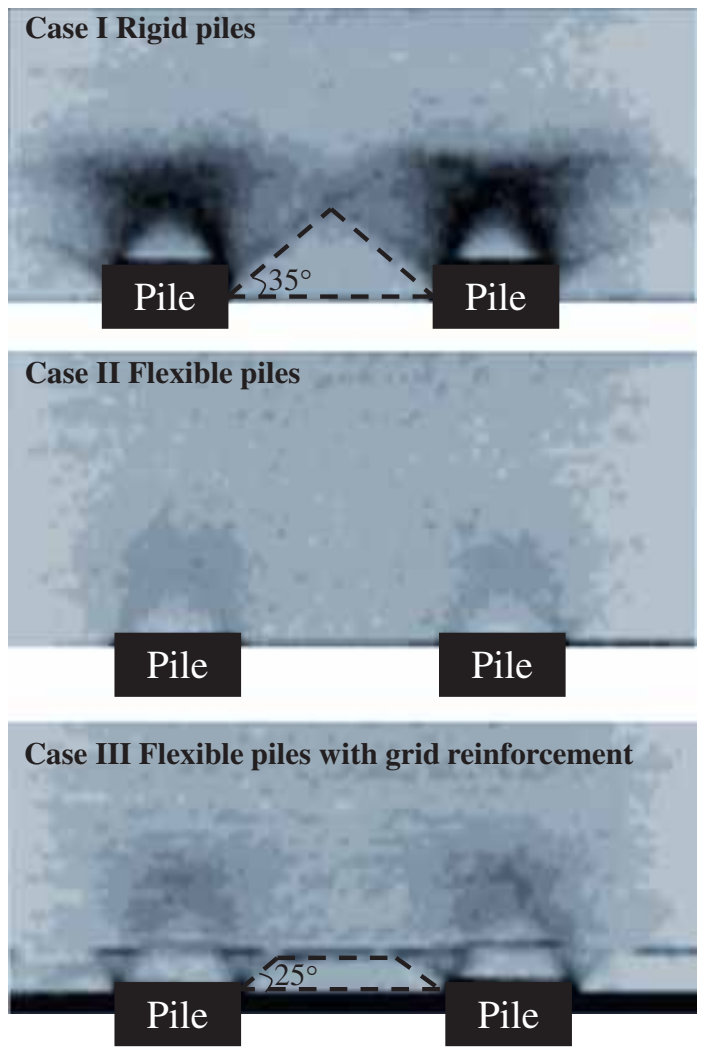

CT-Value

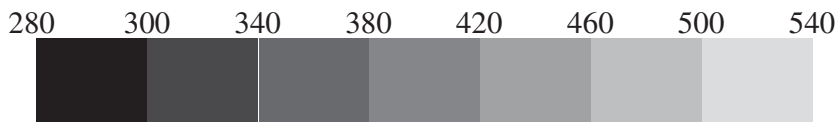

Figure 4. Vertical cross sectional images at $5 \mathrm{~mm}$ settlement in cases of rigid piles - Case I, flexible piles - Case II, and flexible piles with geogrid reinforcement - Case III, from top to bottom, respectively. 
Table 2. Pile loads and settlements of soil.

\begin{tabular}{lcccc}
\hline \multirow{2}{*}{ Settlement $(\mathrm{mm})$} & \multicolumn{2}{c}{ Pile load $(\mathrm{N})$ with/without Geogrid reinforcement } & \multicolumn{2}{c}{ Differential settlement of soil (mm) } \\
\cline { 2 - 3 } & Case II & Case III & Case II & Case III \\
\hline 1 & 6.81 & 10.20 & 0.44 & 0.16 \\
5 & 25.52 & 34.00 & 0.90 & 0.20 \\
& 37.44 & 51.00 & 1.92 & 0.80 \\
\hline
\end{tabular}

of the settlement of the subsoil, which is the area defined in the darkest shade in Case I. The shear planes and dilatancy within the piled embankment results in a decrease of the density of the soil in the arch which is defined by low density areas. The high density area above arching represents the initial density condition of the specimen as well. In Case I, the angle, $\theta$ is about $35^{\circ}$. This result is verified by the previous work of Eskişar et al (2012). The top of the ring shape is clearly flattening in the figure, emphasizing the border of shearing zone, which occurred at the end of the settlement.

In Case II, an area of high density with cone shape at the head of the piles is surrounded by a lower density area at $5 \mathrm{~mm}$ settlement, but this time a shear zone is not formed and soil arching between the piles is not observed clearly.

Case III with grid type of reinforcement shows piles and geogrid carrying the total load at the end of $5 \mathrm{~mm}$ settlement. The lower density area above the pile heads extends in horizontal direction and about to unite with each other. Soil arching is observed in the area which is below the grid and between the piles with a trapezoid shape. The angle of density change is $25^{\circ}$. The cone shaped high density area barely continues above the grid as it is related to deformation and opening size of the grid.

The loads carried by the flexible piles and differential settlement of soil are also calculated by observing the shortening of springs inside the piles in 1-3-5 $\mathrm{mm}$ settlement conditions. The order of loads carried by the pile-reinforcement system is as follows: Load acting on flexible piles and load transferred via grid reinforcement to the piles are bigger than the load acting directly on flexible piles (table 2). The external dead-load and the embankment load are transferred to the top of piles and this mechanism becomes more efficient when arching occurs and the grid type of reinforcement transfers the load to piles via its tension. The load carrying capacity increases between $25 \%$ and $33 \%$. Due to the settlement of pile heads, there is a smaller differential settlement between the piles and the subsoil. It is seen that the majority of the settlement is compensated by flexible pile heads becoming more distinctive in the case of grid type of reinforcement. As seen from table 2, the reduction of differential settlement is around $35 \%$ when compared with only piled embankment case.

It should be kept in view that this study shows the preliminary results obtained by considering the behavior of flexible piles. In further studies there could be more detailed discussion about the effect of stiffness of the reinforcing elements for Case III by using products with different tensile strengths. The spring coefficient representing the flexibility of the piles used in Cases II and III can be changed by applying different types of springs.

\section{Conclusions}

In this study, the load distribution mechanism in reinforced and piled embankments is evaluated quantitatively and X-ray CT method was used as a non-destructive testing technique to examine the soil behavior. The arching of soil between the piles was clearly observed in the case of 
rigid piles and in the case of flexible piles with grid type of reinforcement. Pile load and settlement relations in unreinforced and reinforced cases were compared. It is seen that the increment of load carrying capacity may reach up to $33 \%$ by using geogrid reinforcement. The differential settlements could be reduced to $35 \%$. Lastly, it is concluded that using X-ray CT method and visualization techniques provides a better understanding of soil behavior in a reinforced embankment with the flexible pile foundation system.

\section{Acknowledgements}

This study was held at X-Earth Center in Kumamoto University, Japan. The author is very grateful to Professor Dr. Jun Otani, the Head of X-Earth Center, for his support and guidance. Special thanks are due to Mr. Junichi Hironaka (PhD), Mitsui Chemical Industrial Products, LTD, Saitama, Japan.

\section{References}

Abusharar S W, Zheng J J, Chen B G and Yin J H 2009 A simplified method for analysis of a piled embankment reinforced with geosynthetics. Geotext. Geomembr. 27(1): 39-52

British Standard BS8006-1 2010 Code of practice for strengthened/reinforced soils and other fills. ISBN 9780580538421

EBGEO 2010 Empfehlung für den Entwurf und die Berechnung von Erdkörper mit Bewehrungen als Geokunststoffen. In: Bewehrte Erdkörper auf punkt- oder linienförmigen Traggliedern Deutsche Gesellschaft für Geotechnik e V, (German Geotechnical Society), Ernst and Sohn, ISBN 978-3-43302950-3 (Kapitel 9)

Eskişar T, Otani J and Hironaka J 2012 Visualization of soil arching on reinforced embankment with rigid pile foundation using X-ray CT. Geotext. Geomembr. 32(3): 44-54

Guido V A, Knueppel J D and Sweeney M A 1987 Plate loading test on geogrid reinforced earth slabs. Proceedings of Geosynthetics, New Orleans, 216-225

Han J and Gabr M A 2002 Numerical analysis of geosynthetic-reinforced and pile-supported earth platforms over soft soil. J. Geotech. Geoenviron. Eng. 44: 44-51

Handy R L 1985 The arch in soil arching. J. Geotechn. Eng. 111(3): 302-318

Hewlett W J and Randolph M F 1988 Analysis of piled embankment. Ground Eng. 21(3): 12-18

Jenck O, Dias D and Kastner R 2007 Two-dimensional physical and numerical modeling of a pile-supported earth platform over soft soil. J. Geotech. Geoenviron. Eng. 133(3): 295-305

Kak A C and Slaney M 1988 Principles of computerized tomographic imaging. IEEE Press

Kempfert H G, Göbel C, Alexiew D and Heitz C 2004 German recommendations for reinforced embankments on pile-similar elements. In: Proceedings of 3rd European Geosynthetics Conference Eurogeo3, Munich, Germany, 279-284

Mc Kelvey III, J A 1994 The anatomy of soil arching. Geotext. Geomembr. 13: 317-329

Otani J 2003 State of the art report on geotechnical X-ray CT research at Kumamoto University. In: Otani J and Obara Y (eds), X-ray CT for Geomaterials: Soils, Concrete, Rocks International Workshop on X-Ray CT for Geomaterials, Keynote Lecture, Kumamoto, 6-7 November 2003 Balkema, Netherlands

Russell D and Pierpoint N 1997 An assessment of design methods for piled embankments. Ground Eng. 30(11): 39-44

Terzaghi K 1943 Theoretical soil mechanics. New York: Wiley

Van Eekelen S J M, Bezuijen A, Lodder H J and van Tol A F 2012a Model experiments on piled embankments Part I. Geotext. Geomembr. 32: 69-81

Van Eekelen S J M, Bezuijen A, Lodder H J and van Tol A F 2012b Model experiments on piled embankments Part II. Geotext. Geomembr. 32: 82-94

Van Eekelen S J M, Bezuijen A and van Tol A F 2013 An analytical model for arching in piled embankments. Geotext. Geomembr. 39: 78-102 